\title{
Access, Computational Analysis, and Fair Use in the Digitized Nineteenth- Century Press
}

\author{
PAUL FYFE
}

This essay pivots from questions of copyright in the nineteenth century to the copyright restrictions faced by scholars in the present moment. For periodicals researchers especially, digital collections have seeded a new thicket of issues related to the access, licensing, and ownership of digital content. ${ }^{\mathrm{I}}$ For anyone studying the nineteenth-century periodical press, digital collections inevitably condition much of the research we undertake. Patrick Leary and others have suggested that the scope of what is digitized and digitally accessible exerts a strong historiographic influence on published scholarship. ${ }^{2}$ Intellectual property restrictions are among the major forces shaping the horizon of digital research collections: what gets digitized, what is made available, and how and where it can be accessed. These restrictions are rooted in the nineteenth-century periodical history this issue endeavors to study. They further branch into the legal contingencies attending twentieth-century modes of reproducing the periodical archive. And they are complicated by emerging modes of accessing the archive: not only digital access to copies but computational analysis of entire collections through the use of text and data mining.

This essay, then, moves from copyright issues in nineteenth-century periodical discourse to the international landscape of copyright, commercially licensed digital resources, and fair use which shape periodicals scholarship today. Arguments about access do not fully account for the complex landscape of rights and exceptions for materials ostensibly in the public domain. This landscape is also changing with the emergence of computational research methods, including text and data mining. I argue that exceptions to copyright law for text and data mining might point to new forms of scholarly communication, particularly transformative uses that work around some of the restrictive vestiges of copyright law. Ultimately, 
this essay claims that scholars need to understand the changing parameters of copyright and fair use (or "fair dealing" in the United Kingdom), not simply as it affects our day-to-day work but as an opportunity to shape the law and advocate for creative forms of research and scholarly communication.

\section{Collections and Copyrights}

It has become commonplace to observe the dramatic expansion of access to nineteenth-century books and periodicals because of digitization projects. As several scholars have pointed out, it is problematic to assume that these materials adequately represent the nineteenth-century archive, even though a vast collection of materials has been digitized. Leary notes that despite moves away from "traditional notions of canonicity" in cultural and periodical studies, digital resources may enshrine a new canon based on what scholars can easily access. ${ }^{3}$ And, as Lara Putnam argues, the "new topography of information has systematic blind spots" which may recapitulate the politics of canonicity. ${ }^{4}$ For instance, Alexis Easley has noted the "new canon" of digital collections of nineteenth-century women's writing which privilege volume editions at the expense of women's periodical publishing. ${ }^{5}$ Ben Fagan has pointed to the "racial politics of periodical digitization," specifically the exclusion of many black newspapers from the Chronicling America collection of historical US newspapers. ${ }^{6}$

To identify and redress these problems, scholars are turning critical attention upon the histories of digital collections themselves, documenting the provenance of how digital research collections came to exist. ${ }^{7}$ These histories have identified the downstream effects of corporate decisions, technical specifications, and legacy media on the new media of historical scholarship. Copyright also plays an important role. But too often copyright has been oversimplified into a question of its duration: in other words, copyright terms eventually expire for historical works whereupon they enter the public domain. From this perspective, "out of copyright" materials seem readily available for digitization, promising to make the "nineteenth-century past more readily knowable and open to scrutiny than ever before," as even Leary claims. ${ }^{8}$ As a function of time alone, the nineteenth century apparently beckons with the privilege of its legal availability. In his book Macroanalysis, Matthew Jockers bemoans the copyright restrictions involved in studying twentieth-century works: "Today's digital-minded literary scholar is shackled in time; we are all, or are all soon to become, nineteenth centuryists." This rhetoric periodizes the nineteenth century as somehow digitally liberated and reinforces problematic notions of its digital adequacy. Jockers, whose work concentrates on prose fiction, also mistakes the limited degree to which "public domain" sta- 
tus has shaped periodical digitization. The continuing impact of copyright and commercial licensing on digital periodical collections tells otherwise. Determining what is in the public domain is not the only-or perhaps even the most significant-problem we face as scholars.

Complications arise because of three major factors: I) periodicals are, by definition, issued over time, and the rights for nineteenth-century materials may remain tangled with their continued publication into copyrighted time frames, 2) many digitization projects-especially for British newspapers and periodicals-have been undertaken by commercial providers or as public-private partnerships, requiring varying degrees of licensed access, and 3) exceptions to copyright, proposed by legal scholars and advocates to make copyright more responsive to digital media, are subject to uneven international laws as well as problems of technical interoperability. Ultimately, casual and computational access to "public domain" materials, not to mention scholars' rights to publish or use examples from these collections, is far more complicated than a matter of copyright duration.

The British Library's newspaper digitization efforts offer a case study of these complexities. It began digitizing its newspaper collection in the mid2000 s with funding from the Joint Information Systems Committee (JISC), editorial guidance from a team of scholars, and technical assistance from external vendors. Ed King, former director of the library's newspaper collections, has documented many of these projects' legal considerations and how the library responded. ${ }^{\text {10 }}$ For instance, the extent of historical newspapers to be included was immediately affected by questions of copyright and commercial interests. Several newspaper titles that were still being published (such as the Guardian or Daily Telegraph) were quickly ruled out because of their owners' interests in digitizing and vending their back issues. ${ }^{\text {II }}$ The British Library then faced two distinct challenges: assessing the rights of newspaper proprietors and, in the case of signed articles, the rights of individual authors. ${ }^{\mathrm{I2}}$

Determining the ownership and copyright of historical newspapers became quite complex, as newspapers often merged or were incorporated under different titles or were owned in partnerships. The British Library's project team looked back to the I9I I Copyright Act, which extended the terms of a previous 1842 act to protect copyright for the life of the author plus an additional fifty years and enshrined the rights of periodical proprietors as the owners of collective works. ${ }^{13}$ Based on those parameters, the British Library's team played it extremely safe, deciding that newspapers published before I 865 could be deemed completely out of copyright. That covered thirteen of the project's forty-eight selected titles. For the other thirty-five titles published after I 865 , the decision depended upon "establishing the date of death of the proprietors of each newspaper"- 
a task which proved incredibly tricky and, in several cases, impossible. ${ }^{14}$ The library employed a specialist firm to comb press directories, scour the National Archives at Kew, and peruse biographical histories to determine, first, proprietorship of selected newspapers and, second, their death dates. The library established a workflow so that, for the twenty-seven of fortyeight newspapers where these answers could not be settled, it could at least demonstrate due diligence. It then contacted publishers via post to explain the library's digitization plans. Very few answered. As King explains, "The Library realised that publishers had not formed a view as to the value of the historic runs of newspapers that they owned." Is

The British Library also worried about individual signed articles within the collection. Those copyrights remained with the authors unless they contractually relinquished them to the publisher. According to the I9I I act, these rights applied to the first publication of their work, as well as to subsequent republication, for the life of the author plus fifty years. These terms would require the British Library to determine, after their cutoff date, who owned the copyright for every article and every republished article in the newspapers they sought to digitize and republish online. The library realized the prohibitive labor involved in researching every instance of a signed article (to say nothing of the labor involved in tracking unsigned contributions), including the biographical details of authors and the unlikely record of any contracts they might have signed. ${ }^{16}$ So they decided on a "wait and see" approach, lamenting the lack of national and international standards for identifying "orphan works"-those publications potentially still in copyright whose owners could not be determined or those that otherwise relinquished the rights to their productions. ${ }^{17}$

It could be argued that the British Library used a very conservative interpretation of the law-and may have gone to unnecessary trouble. By using the proprietor's death date to establish the term of copyright, the library observed section I 8 of the I 842 Copyright Act. But as Elena Cooper demonstrates, this section pertained only when newspapers could show they had paid their contributors with the understanding that copyright would transfer to the proprietor. ${ }^{18}$ Of course, substantial amounts of what appeared in nineteenth-century newspapers went unpaid or were reprinted from elsewhere. Newspaper proprietors only began to document the transfer of contributors' rights beginning in the $\mathrm{I} 890 \mathrm{0}$ and afterwards. ${ }^{19}$ Furthermore, as Alexis Easley argues, even if author payments and the transfer of rights could be documented, in practice, the courts only actively protected periodical contents that seemed to have "literary merit." ${ }^{20}$ The copyright status of periodical content was a gray area throughout the nineteenth century, and, as the British Library's procedures suggest, this ambiguity continues to present troublesome questions during the processes of digitization. 
The legal status of historical materials is not the only factor determining access to nineteenth-century newspapers. The contemporary labor of digitization entangles these collections anew in copyright disputes. In I998, new regulations came into force in the United Kingdom that extended copyright to databases and provided even stronger protections to some databases as sui generis property. This database right, lasting for fifteen years from creation, subsists if there has been "substantial investment in obtaining, verifying, or presenting the content." ${ }_{21}$ Thus, databases which collect out-of-copyright materials may still be protected by the capital investment, digital architecture, and delivery systems they employ.

The British Library had initially planned to create its own online platform for users to openly access its digitized newspapers but instead chose to partner with external vendors to transform scanned page images into searchable documents and then to create a web interface. These vendors included Gale Cengage, which was responsible for the initial release of the I9th Century British Library Newspapers collection, and then Findmypast, a genealogy company which has the current contract for the British Newspaper Archive. As a result of what one project manager called an "innovative and challenging example of a public/private partnership," the British Library's digital newspaper collections became subject to commercial licensing and access restrictions. ${ }^{22}$ Users could freely access the database from within the British Library or a consortium of universities; beyond that, commercial licensing fees applied. In the United States, Gale sold institutional subscriptions to academic libraries. ProQuest began selling access to its British Periodicals collection at about the same time. Findmypast has its own complex system of paywall access to the British Newspaper Archive depending on the user and the institutional location. Andrew Prescott, professor of digital humanities at the University of Glasgow, complains that this has resulted in a "kind of digital dance of the seven veils" for researchers, the rise of a moneyed class of academic consumers, and even the "theft of public cultural property" by commercial publishers. ${ }^{23}$

Prescott argues that the British Library's digitization projects, especially its historical newspaper collections, represent nothing less than the "enclosure of our cultural commons" for the profit of private enterprise. ${ }^{24}$ The library counters this claim by asserting that such projects could not have happened without external partnerships and that the resulting availability of historical materials justifies the compromise. But there are other institutional models for digitization. The National Library of Wales acquired funding from the Welsh government, the JISC, and the European Regional Development Fund for its periodical digitization projects, including Welsh Journals and Welsh Newspapers Online. According to Dafydd Tudur, the 
library's rights and information officer at the time, they used a similar workflow to manage questions of historical copyright, remaining in close contact with Ed King at the British Library. ${ }^{25}$ Yet they accepted a different legal argument that materials published before I88I were demonstrably in the public domain. ${ }^{26}$ For materials published after that date, it was not viable to search for every author of every article, so they tried to trace the historical rights to newspaper content. They contacted over fifty organizations-including commercial entities, religious organizations, and even a high school in south Wales - to explain the library's plans to digitize newspapers up to the year I9I9. All who replied were happy to see the project proceed; only five claimed ownership of newspaper titles. In its web interface, Welsh Newspapers Online identifies the probable copyright status of each piece of content, whether it is copyrighted, public domain, or unknown. Rights holders can respond and claim ownership of content as needed.

Welsh Newspapers Online is entirely open access, built with public funding and in-house expertise. The National Library of Wales does not claim copyright on its own digital reproductions, offering them, wherever possible, under creative commons licenses for non-commercial use. Lorna Hughes, a former research chair in digital collections at the library, explains that "underpinning all NLW digitisation is the underlying principle of freely available public digital collections." ${ }^{27}$ Like Prescott, Hughes interprets historical materials as being part of a cultural commons. ${ }^{28}$ The goal of digitizing cultural heritage materials is to answer the public's right to memory and then to create, in the context of newspaper collections, a "digital public sphere." ${ }_{29}$ Prescott and Hughes each understand copyright from the position of public interest, rather than commercial protections. Of course, disputed concepts of "public interest" and the "commons" vary with the history of British property law. As Isabella Alexander suggests, the problem is less "whether copyright should serve the public interest, but which version of the public interest should take priority, and how it should interact with property rights." ${ }^{\circ}$ That problem has acutely changed with digital media.

Scholars are familiar with the frustrations of uneven access to digitized materials, particularly historical records whose originals, at least, are in the public domain. ${ }^{3 \mathrm{r}}$ At my first academic institution, Florida State University, the libraries subscribed to Gale's I 9th Century British Library Newspapers, but when I changed institutions, my new university had no subscription. Until very recently I had to drive more than twenty-five miles from Raleigh to the Davis Library at the University of North Carolina-Chapel Hill and sit in front of a specified computer terminal to access the database. Access was courtesy of a consortium agreement between the NCSU Libraries and 
University of North Carolina Libraries. That agreement includes searching across all catalogs and, upon request, delivering books by van throughout North Carolina's Research Triangle. Consider the paradox: thanks to the internet, books can freely travel but e-books and databases cannot.

Such restrictions answer the profound unease that commercial providers have about their data escaping into the wild. A copyright librarian at my institution told me that the majority of the complaints the library fields from its commercial partners are about systematic downloads, which they fear will be reposted for sale or made available elsewhere. In the United States, copyright governing what libraries can do with purchased digital collections goes back to micropublishing in the r930s (in other words, microfilm and microfiche). In I935, a group of scholars and publishers established rules called the "Gentlemen's Agreement" which allowed researchers to obtain non-commercial copies of textual works. ${ }^{32}$ This arrangement held for several decades until the photocopier emerged, which was apparently ungentlemanly enough to require new rules, codified in section I08 of the I976 US Copyright Act. Section I08 allows an exemption for libraries, archives, and museums to help researchers make copies for non-commercial use. The United Kingdom also allows some exceptions for libraries, including providing dedicated access and copies for individual research purposes..$^{33}$ As with the photocopier, the advent of the digital copy has put new pressure on the rules which, once again, need to be updated for the digital world. ${ }^{34}$

Digital copying seems at once an incredible boon for sharing resources and an existential threat to commercial media providers. It has created a wildly uneven landscape upon which publishers, librarians, archivists, and researchers must balance the values of scholarly communication against the institutional realities of access. Some projects, like Welsh Newspapers Online, the Australian newspapers collections at Trove, the Old Bailey Online, and Dickens Journals Online are happy to share their collections and release them for all sorts of uses. Yet many digitized historical sources are generated by public-private partnerships or commercial entities and perhaps could not have been produced otherwise. Hughes concedes that "scholarly digital resources created by the sort of funding available to the humanities cannot compete with the scale of resources created by commercial publishers." ${ }^{35}$ For Hughes, this means being more strategic about the open, non-commercial collections that we do make. At the same time-and perhaps especially in the field of periodical studies-researchers have to reckon with the day-to-day challenges of restricted access and varied forms of licensed use.

In their book Reclaiming Fair Use, Patricia Aufderheide and Peter Jaszi try to shift the conversation about access, arguing that a singular commit- 
ment to open access and creative commons has "ceded the crucial ground of the public interest within copyright" by looking for a better world elsewhere. ${ }^{36}$ As they suggest, open access cannot be the only answer: researchers need to assert their rights within the framework of the law, including "fair use" in the United States and "fair dealing" in the British Commonwealth. According to Aufderheide and Jaszi, working from within the parameters of copyright actually allows researchers to expand their rights and support the public interest. This requires changing our research paradigm from being consumers of protected materials to becoming active participants within the framework of the law. As Robin Wharton argues, confronting these legal paradigms will be crucial to how the humanities defines itself as a profession, particularly as our materials and research methods change through digital means. ${ }^{37}$

\section{Licensed, Fair, and Computational Uses}

Digitization has not necessarily freed nineteenth-century British periodicals from copyright restrictions, but it has changed scholarly research methods. How, also, might it change scholars' uses of works protected by copyright? Such uses can take different forms, including licensed use as well as copyright exceptions, including "fair use" in the United States and "fair dealing" in the British Commonwealth. There are important differences between them. Fair dealing, for instance, defines specific categories of acceptable use from the outset: uses of copyrighted materials for research, private study, criticism, review, or reports on current events. Fair use, by contrast, offers much greater flexibility as it considers the qualities rather than the categories of use. The 1976 Copyright Act in the United States specified four factors that courts should consider in determining whether the use was fair:

- The purpose and character of the use,

- What materials are actually being used,

- The amount and substantiality of the materials used, and

- Any market harm caused by the usage..$^{38}$

The flip side of flexibility is ambiguity. These somewhat vague statutes are subject to interpretation. They do not always specify exact amounts or venues of use, and so many libraries, universities, and academic publishers recommend or impose arbitrary rules on the amount of copyrighted material a researcher or teacher might employ (for example, 250 words of a long poem). ${ }^{39}$ The other major problem is that the 1976 Copyright Act defines fair use primarily in response to the photocopier. Digital commu- 
nications technologies require very different parameters for what should be fairly allowed..$^{\circ}$ But because fair use is determined by the courts on a case-by-case basis, the extent of its applications in digital form can seem unclear. Individual researchers often shy away from testing its limits or get discouraged from even trying by anxious gatekeepers.

In using licensed material, researchers often find conflicting advice about everything from formal permissions to posting screenshots online..$^{\mathrm{I}}$ The scale of digital research can also strain accepted practices. What is, for example, fair use of seven terabytes of data? This was the question I naively asked my university's copyright librarian upon receiving Gale's I9th Century British Library Newspapers collection on several physical hard drives. Given the scale of what is digitally available to researchers, fair use (or fair dealing) guidelines can seem like vestigial remnants of a world of print weakly imposed upon the "amount and substantiality" of vast digital collections or the changing practices of digital research and scholarly communication. In the United States, United Kingdom, and the European Union, a number of non-profit and government-sponsored research groups are researching and advocating copyright reform in digital contexts. Their goals include updating experiences for the consumers and producers of digital media, establishing fair protections for the market, and enabling digitization opportunities for cultural heritage organizations, as well as for new methods for research.

For scholars interested in the large-scale analysis of historical materials, these issues came into focus with legal challenges to the Google Books project and the HathiTrust Digital Library. These projects scanned huge swaths of books, including in-copyright books, without first seeking permission from rights holders. But a search result or "hit" did not mean users could access a restricted document. Google's data remained accessible only by searching and computation, but the fact that Google possessed "copies" of books on its servers-including still copyrighted post-I923 materials-was legally contested by the Authors' Guild. Interestingly, the defense found help within the digital humanities community. Matthew Jockers, among others, helped to file two amicus briefs on behalf of Google and HathiTrust. ${ }^{22}$ These briefs argue that making copies for digital searching is not like Xeroxing because what people do with those copies is different from reading. As opposed to keeping "durable copies" of protected material, computer analysis uses only "transitory copies," which are not individually accessible. ${ }^{43}$ Data and text mining these copies represent "non-expressive use," which Google and HathiTrust claimed as fair use. The HathiTrust Research Center proposes a related term, "non-consumptive use," which fairly allows researchers data-level access to in-copyright materials without direct access to reading for intellectual content. ${ }^{44}$ What 
HathiTrust calls a "non-consumptive research paradigm" affords all kinds of new approaches to content at scale, including materials still covered by copyright. ${ }^{45}$ In late 2013 , a federal judge of the US district court accepted these arguments to allow copyrighted materials for non-consumptive research. ${ }^{46}$

Even though Google is a private company that monetizes access to "transitory copies" on its servers, scholars and librarians came to its defense in the service of the public good, urging the US courts to consider access to knowledge-and especially humanities knowledge-in its corpus of books. In the United Kingdom, revisions to copyright law have occurred under broader governmental mandates, in which text and data mining exceptions have been framed as catalysts for scientific progress and economic growth. In 20I0, David Cameron ordered a review of how the United Kingdom's copyright framework might respond to a changing digital landscape. Ian Hargreaves, a professor of digital economy at Cardiff University, published a response with help from the Intellectual Property Office in 20 I I which emphasizes "Intellectual Property (IP) policy [as] an increasingly important tool for stimulating economic growth." ${ }^{77}$ Hargreaves does urge the government to consider the precedent of the Google Books case, as well as the "vast treasure trove of copyright works which are effectively unavailable-'orphan works." " ${ }^{8} 8$ A follow-up report from the JISC in 2012 on the "Value and Benefit of Text Mining" also advocates for text and data mining in terms of the scientific innovation and economic impacts it might bring to the United Kingdom. ${ }^{49}$ Though the digital humanities have featured less prominently as a justification for greater access, these arguments have been effective. In 20I4, the United Kingdom passed legislation allowing an exception for text and data mining for research projects with non-commercial outputs provided they had legal access to the materials and acknowledged their source..$^{\circ}$

In Europe, the establishment of a legal framework for use of in-copyright works has been a "key action of the Digital Agenda for Europe," which is part of the Europe 2020 strategy. ${ }^{51}$ The general goal is to harmonize EU copyright law with the possibilities of digital works and to allow these works to flow across borders and legislative regimes. Text and data mining exceptions were among the issues the commission sought to address, aiming to "make it easier for researchers across the EU to use text and data mining (TDM) technologies to analyse large sets of data." ${ }_{52}$ Specific proposals are still underway at the time of this article's writing, but they recommend a mandatory exception to copyright for using text and data mining in scientific research. While humanities-based research is not mentioned, these exceptions may have wide application for research on large collections of digital materials. 


\section{Computational and Transformative Scholarship}

There are several examples of how humanities researchers might use copyrighted collections of historical materials at scale. Early on in the Google Books project, the company made the books corpus available, under restricted conditions, to scholars doing computational analysis. These included an interdisciplinary team working at the "cultural observatory" at MIT who published their results in the journal Science, claiming to have invented a new field called "culturomics." ${ }_{53}$ The historians Dan Cohen and Fred Gibbs also received access to Google's dataset, publishing their experiments with nineteenth-century intellectual history in Victorian Studies. ${ }^{54}$ Notably, these teams did not have direct access to the data but provided research questions to Google's engineers who sent back the results.

Academic publishers and commercial resource providers are also considering whether and how to facilitate the querying of restricted data at scale. Open access collections, like the Digital Public Library of America, may offer an application programming interface (API) for direct access. Taking a different approach, JSTOR-which, as the Aaron Schwartz case tragically suggested, disapproves of opening its source data-released a "Data for Research" portal around 2008. The portal provides access to JSTOR's own content-mining and faceted searching tools, including a text analyzer tool released in 2017.55 Also in 2017 , the British Library announced that "users will be able to consume research data online through tools that enable it to be analysed, visualised and understood." ${ }^{6}$ Commercial providers are making similar plans in response to the increased popularity of text-analysis research. Gale introduced Artemis, a product that promises text mining and analysis tools on top of the digital content the company already offers.

These examples also reveal the two distinct problems facing researchers interested in text and data mining: I) simple access to data and 2) the rights to computationally analyze it. Access does not mean simply doing as one likes, especially with digital materials. The entertainment industry knows this very well and has advocated far-reaching copyright protections and developing digital rights management (DRM) technologies to limit the copying and distribution of digital products. Scholarly publishing has implemented paywalls and web-based interfaces which prevent researchers from accessing source data and limit the amounts they can feasibly process through browsers. Even with the legal standing for text and data mining, scholars may face restrictions on how they access data in the first place. Brandon Butler, director of information policy at the University of Virginia Library, asks, "How can we take advantage of the broad rights we have under fair use when control of massive collections of physical copies 
(including bits and bytes on servers) has shifted increasingly to publishers?" ${ }_{57}$

When the United Kingdom passed its text and data mining exception, open-access advocate Peter Murray-Rust optimistically declared, "Content mining starts today!" ${ }^{8}$ The exception has enabled several interesting computational analysis projects which focus on nineteenth-century periodicals, including M. H. Beals's Scissors and Paste project in collaboration with the British Library. In "Content Analysis of I 50 Years of British Periodicals," Lansdall-Welfare et al. critique the MIT "culturomics" team for excluding periodicals from their source data and then analyze the British Library's Findmypast newspaper corpus at scale. ${ }^{59}$ According to UK law, computationally minded researchers do not have to seek permission for text and data mining from the rights holder-but that does not mean providers must readily hand over their files. Murray-Rust is an advocate for "web scraping": establishing scripts to automatically download and collect digital content. ${ }^{60}$ Yet according to UK law, researchers attempting to circumvent publishers' technical restrictions can be sued. ${ }^{6 r}$ In the United States, the I998 Digital Millennium Copyright Act makes it illegal to circumvent the digital rights management protections imposed by publishers-although it also allows Congress to make exemptions in certain contexts. Every three years, the Library of Congress oversees discussion of these exemptions, which could come to include text and data mining. ${ }^{62}$ In any case, many scholars are wary of testing these legal thresholds. And where nineteenth-century periodicals are concerned, the familiar problems of access still apply.

Take again the British Library's digitized newspaper collection. Researchers within the United Kingdom's higher education consortium and within the library itself can access its nineteenth-century newspaper databases as well as its physical collections of print and microfilm (with some restrictions). However, a text and data mining project on these collections is not so simple. If a researcher wants to computationally analyze the British Library's digital copies of its own newspapers, the library must ask permission from Gale Cengage, then submit the researcher's credentials to the library's intellectual property office with a letter of support testifying that he or she has no criminal background. In other words, even the library is not free to do what it likes with its own digital collections. For users outside the United Kingdom, Gale sells content-mining rights to subscribers along with a set of hard drives for purchase. Even the National Library of Wales, with its admirable commitment to open access, has not ruled out charging users to download "public domain" datasets. It feels pressure to develop revenue streams to support itself and must balance the values of openness with the need for fiscal sustainability. 
Furthermore, the availability of data or legal permissions for text and data mining do not change the limitations on what a researcher might publish. The United Kingdom's intellectual property office and JISC offer guides to help researchers with the implications of the text and data mining copyright exception for research. Researchers may publish results that are "simply facts" and are therefore not covered by copyright. ${ }^{63}$ They may quote from originals "as long as the length of the quote used does not undermine the legitimate (often commercial) interests of the rights holders." ${ }^{64} \mathrm{In}$ other words, republishing small amounts of copyrighted materials can be considered fair dealing. Fair use guidelines also apply in US contexts: as counsel for the Association of Research Libraries explains, researchers may publish snippets of original sources so long as their "results do not make the full text, or substantial portions, of the underlying articles publicly available." ${ }^{65}$ Fair use measures do not substantially differ for scholars who study one newspaper article or computationally analyze millions of them. Even so, just as "non-consumptive use" has helped redefine fair use for text and data mining research, there is an emerging category of "transformative use" which may have similar effects on scholarly publishing.

Transformative use took shape in the United States during the I99os following the I 994 landmark case Campbell v. Acuff-Rose Music, which considered 2 Live Crew's parodic remix of Roy Orbison's "Pretty Woman." ${ }_{66}$ In the years since, fair use cases have shifted from assessments of market impact to judgments about whether or not the reuse of copyrighted material is transformative. As Brandon Butler observes, "Courts have shown deference to uses successfully characterized as 'transformative." " ${ }^{67}$ However, those uses have typically come from domains other than education or scholarship. Butler argues that scholars and teachers can and should dramatically expand their uses of restricted materials by shifting to a transformative use paradigm. Given the imbalance between the publishing limits of fair use and the scale of digitized source material, transformative use in US law may offer a new "publishing paradigm" parallel to the "research paradigm" of text and data mining, with similar exceptions to copyright.

What might transformative use look like in digital periodicals scholarship? Dallas Liddle's work with the Times Digital Archive has used data analysis to identify large-scale features of that newspaper over time. ${ }^{68}$ Liddle generates graphs which transform that data into a visual argument supplementing the narratives of his articles. However, due to Gale's licensing terms and academic publishers' guidelines, we cannot access the thousands of texts and images behind these arguments. ${ }^{69}$ In its studies of reprinted texts in nineteenth-century US newspapers, the Viral Texts project also generates network graphs and maps but has the benefit of openaccess materials from the Library of Congress that it can also freely share. 
The HathiTrust Research Center may suggest another way forward. It extracts "features" of its in-copyright source texts, including word counts, parts of speech, term frequencies, and page locations. Sayan Bhattacharyya, formerly of HathiTrust, claims that these features present a "translation of the text" between human and machine languages. ${ }^{70}$ Furthermore, they can be recombined "into ludic, ambiguous, open-ended wholes"-a more performative approach to scholarship than quantitative analysis suggests. ${ }^{7 \mathrm{I}}$ What this looks like is less clear. But Bhattacharyya's claim starts to explore how the problems of copyright could compel entirely new forms of scholarship.

Transformative use might prompt scholars to consider transforming their habits of inquiry. In her article "Digital Humanities, Copyright Law, and the Literary," Robin Wharton provocatively argues that the history of copyright law has enforced a categorical separation between what scholars publish and what they study. In other words, copyright law pushed literary scholarship into a familiar mode of critique distinct from those texts it could not legally reproduce. Copyright helped enshrine a hermeneutics of suspicion at the expense of compositionist and creative modes of scholarship, including those made newly possible by digital publishing formats. In imagining what those might be, Mark Sample has urged digital scholars to move beyond text and data mining to more creative acts. What he calls the "poetics of machine reading" would make creative use of the computational engines behind non-expressive techniques. ${ }^{72}$ While Sample points to new media art for inspiration, Tim Sherratt, the former director of Trove, has developed a number of such innovative approaches to historical newspapers. For example, Sherratt has built a harvester to collect front pages of newspapers as well as accompanying metadata. Using this tool, researchers can explore page design and content type for millions of front pages in the collection. Sherratt wants researchers to "to move beyond the search box to find new ways of exploring and contexualising [newspaper] content." 73 His approach also demonstrates what transformative modes of publishing restricted content might look like-through aggregations of images like The Front Page, through their transformative contextualization, as in The Real Face of White Australia, or even through more experimental applications like Headline Roulette. All these examples suggest creative, critical, and even polemic strategies for transforming digital historical materials.

What are the horizons for transformative scholarship in Victorian studies? Will such transformative uses be recognized as scholarship? Amid the legal, technical, and institutional pressures on access to digital materials, there are many challenges far exceeding the field of nineteenth-century studies. Yet periodicals from that era usefully embody many of the opportunities and ironies of digital access. If, in the nineteenth century, 
the ambiguous status of copyright in periodicals allowed a particular literary and information culture to flourish, then periodicals scholars have a similar opportunity to design new forms of scholarly analysis, public engagement, and communication within the shifting parameters of the law. As Mark Rose suggests, copyright does more "than govern the passage of commodified exchanges across the boundary between the private sphere and the public; it actually constitutes the boundary on which it stands." 74 With so many of our digital resources located on that contested boundary, nineteenth-century scholars must continue to engage with contested rights and new opportunities for transformative production.

North Carolina State University

\section{NOTES}

I. I presented an early version of this paper at the 2015 meeting of the Scholarly Communication Interest Group for the Association of College and Research Libraries' New England Chapter. My deep thanks to Ed King of the British Library (retired), Will Cross of NCSU Libraries, Ulrich Tiedau at University College London, and Dafydd Tudor at the National Library of Wales for their assistance developing these ideas through emails and Skype calls. I am also grateful to Will Slauter, Elena Cooper, Aileen Fyfe, Noah Moxham, Melodee Beals, Laurel Brake, Jim Mussell, and Lionel Bently for the stimulating exchanges at the "Copying and Copyright in NineteenthCentury Newspapers and Periodicals" 2017 workshop at the Université Paris Diderot.

2. Leary, "Googling the Victorians." This bias potentially includes an undue focus on copying itself. Duplicated texts, unlike other kinds of research problems, are computationally traceable.

3. Ibid., 82. Andrew Prescott also cautions against the "new and unlooked for canonicities" that emerge based on hierarchies of access. See "Dennis the Paywall Menace." For a case study, see Milligan, "Illusionary Order."

4. Putnam, "Transnational," 379.

5. Easley, "Chance Encounters," 706.

6. Fagan, "Chronicling White America," Io.

7. For examples, see Mak, "Archaeology of a Digitization"; Cordell, "Q i-Jtb the Raven"; Gadd, "Use and Misuse of Early English Books Online"; Fyfe, "Archaeology of Victorian Newspapers"; Gabriele, "Transfiguring the Newspaper"; Hardy, "Bibliographic Enterprise and the Digital Age."

8. Leary, "Googling the Victorians," 79. Even Bob Nicholson, who acknowledges the limits of access to commercial databases, suggests that "Victorian print culture is no longer subject to copyright protection." See "Counting Culture," 240. 
9. Jockers, Macroanalysis, I73.

ı. King, "British Library Digitisation."

I I. Shaw, "Io Billion Words," 3 .

I2. Copyright protection did not depend on a contribution being signed, but it is more difficult to trace the potential ownership of unsigned articles.

I3. "Copyright Act I9I I," s. 3, s. 24 (provision for existing works). Note that the first schedule of the I9I I act referred back to section I 8 of the I 842 Copyright Act to state that in the case of existing contributions to periodical works, authors retained rights to subsequent republication unless there had been a different agreement with the proprietor of the periodical.

I4. King, "British Library Digitisation," 8.

I 5. Ibid.

I6. Ibid., 9 .

I7. Ibid., 2I. The European Commission did not release its orphan works directive with best practices until 2OI 2 ("Directive 20I2/28/EU").

I8. See Elena Cooper's contribution to this special issue.

I9. See Slauter, Who Owns the News?, chapter 5.

20. Easley, "Nineteenth Century," forthcoming.

2I. "Copyright and Rights in Databases Regulations," s. I 3 (I).

22. Shaw, "British Newspapers," 8.

23. Prescott, "Dennis the Paywall Menace."

24. Ibid.

25. See Tudur, "Getting It Right."

26. This argument was developed by Tim Padfield and Ronan Deazley for the Intellectual Property Office in "Consultation on Reducing the Duration of Copyright," 20.

27. Hughes, "Live and Kicking."

28. See also Jim Mussell's critique of the British Newspaper Achive, including "having to pay for access to what is already public property" ("British Newspaper Archive”).

29. Hughes, "Live and Kicking." See also Hughes, “The Public Has a Right to Memory."

30. Alexander, Copyright Law and the Public Interest, I I 2; her emphasis.

3I. The problem is compounded for independent scholars. See Werner, "Researching While Unaffiliated."

32. United States Copyright Office, "Section Io8 of Title I7," 5.

33. "Copyright, Designs and Patents Act I 988 ," amended sections $40 \mathrm{~A}$ to 43 , http://www.legislation.gov.uk/ukpga/I 988/48/part/I/chapter/III/crossheading/libraries-and-archives.

34. The US Copyright Office has released a "discussion document" pertaining to these issues, including the possibility of text and data mining. United States Copyright Office, "Section I08 of Title I7," I.

35. Hughes, "Live and Kicking." 
36. Aufderheide and Jaszi, Reclaiming Fair Use, 48.

37. Wharton, "Digital Humanities."

38. For a useful history of US fair use law, see Aufderheide and Jaszi, Reclaiming Fair Use.

39. Johns Hopkins University Press, the publisher of Victorian Periodicals Review, has no set word count for using copyrighted material and decides permissions on a case-by-case basis.

40. Conversely, digitization projects need to approach the creation of new resources as more than "digital photocopying." Hughes, "Live and Kicking."

4I. For example, the British Newspaper Archive attempts to prohibit users from sharing "copies of any of the newspapers (either an original image of the newspapers or the information on the results page)." Its terms of service are quoted in Mussell, "British Newspaper Archive." The legality of these restrictions is highly debatable with respect to fair use and fair dealing.

42. Jockers, Sag, and Schultz, "Brief of Digital Humanities," $20 \mathrm{I}_{2}$ and $20 \mathrm{I}_{3}$.

43. Cox, "Text and Data Mining," I.

44. Butler, "Operationalizing 'Non-Consumptive' Fair Use.” Borghi and Karapapa use the term "non-display use" and analyze its legal implications in "Non-Display Uses of Copyright Works."

45. "Our Research Center." HathiTrust also planned to release openly a set of orphaned works, but the project stalled amid the Authors Guild lawsuit, and, with no judicial decision to clarify, it has not been resumed. Albanese, "HathiTrust."

46. Chin, "Google Summary Judgment Final."

47. Hargreaves, "Digital Opportunity," 3.

48. Ibid., 4 .

49. McDonald and Kelly, "Value and Benefits."

50. Intellectual Property Office, "Exceptions to Copyright: Research."

5I. "Directive 20I 2/28/EU," 299/5.

52. "Commission Proposes Copyright Exception."

53. Michel et al., "Quantitative Analysis of Culture."

54. Gibbs and Cohen, "Conversation with Data."

55. Humphreys, "On Beyond Keyword Search."

56. "Announcing."

57. Butler, "For Text and Data Mining."

58. Murray-Rust, "Content Mining Starts Today."

59. Lansdall-Welfare et al., "Content Analysis of I 50 Years of British Periodicals."

60. Murray-Rust, "Content Mining Starts Today."

6I. Kelly, "Text and Data Mining."

62. Scheid, "New DMCA Exemptions." Similarly, some have suggested that the EU exception for text and data mining should include limits on the technical obstacles to data. See Geiger et al., "Opinion of the CEIPI." 
63. Intellectual Property Office, "Exceptions to Copyright: Research."

64. Kelly, "Text and Data Mining."

65. Cox, "Text and Data Mining," I. A notable case over e-reserves at Georgia State University defined this as "de minimis" use with no impact upon the publisher. See Butler, "Transformative Teaching."

66. Aufderheide and Jaszi, Reclaiming Fair Use, 83.

67. Butler, "Transformative Teaching," 2.

68. Liddle, "Genre" and "News Machine."

69. As Susan Brown has claimed, scholars must consider access to digital evidence to evaluate or reproduce computational claims. "Networking Feminist Literary History," 64.

70. Bhattacharyya, "Reading via Fragments."

7I. Ibid.

72. Sample, "Poetics of Non-Consumptive Reading."

73. Sherratt, “4 Million Articles Later."

74. Rose, Authors and Owners, I4I.

\section{BIBLIOGRAPHY}

Albanese, Andrew. "HathiTrust Suspends Its Orphan Works Release.” Publishers Weekly, September I6, 20I I. https:/www.publishersweekly.com/pw/by-topic/ digital/copyright/article/48722-hathitrust-suspends-its-orphan-works-release. html.

Alexander, Isabella. Copyright Law and the Public Interest in the Nineteenth Century. Oxford: Hart, 2010.

"Announcing the New British Library Research Data Strategy." British Library Digital Scholarship Blog (blog), August 25, 20I7. http://blogs.bl.uk/digitalscholarship/20 I 7/08/announcing-the-new-british-library-research-data-strategy.html.

Aufderheide, Patricia, and Peter Jaszi. Reclaiming Fair Use: How to Put Balance Back in Copyright. Chicago: University of Chicago Press, 20I I.

Bhattacharyya, Sayan. "Reading via Fragments: Non-Consumptive Reading as Practical Necessity and as Post-Humanist Performativity." Paper presented at the Experimental Interfaces for Reading 2.0, IIT Institute of Design, January 23, 20I 5. https://vimeo.com/I I 7642860.

Borghi, Maurizio, and Stavroula Karapapa. "Non-Display Uses of Copyright Works: Google Books and Beyond.” SSRN Scholarly Paper. Rochester: Social Science Research Network, April I, 20I I. https://papers.ssrn.com/ abstract $=23589$ I 2 .

Brown, Susan. "Networking Feminist Literary History: Recovering Eliza Meteyard's Web.” In Virtual Victorians: Networks, Connections, Technologies, edited by Veronica Alfano and Andrew Stauffer, 57-82. New York: Palgrave Macmillan, 20I 5 . 
Butler, Brandon. "For Text and Data Mining, Fair Use Is Powerful, but Possession Is Still 9/IO of the Law." SPARC (blog), February 28, 20I 8. https://sparcopen. org/news/20I 8/possession-is-still-9-Io-of-the-law/.

—_. "Operationalizing 'Non-Consumptive' Fair Use to Revolutionize Humanities Research.” HathiTrust Digital Library (blog), February 24, 2017. https:// www.hathitrust.org/blogs/perspectives-from-hathitrust/operationalizing-nonconsumptive-fair-use-to-revolutionize.

_. "Transformative Teaching and Educational Fair Use after Georgia State." SSRN Scholarly Paper. Rochester: Social Science Research Network, February 23, 20I 5. http://papers.ssrn.com/abstract=2568936.

Chin, Denny. “Google Summary Judgment Final.” US District Court of Southern New York, 20I3. http://www.techdirt.com/articles/2OI3 I I I 4/O956I $525242 /$ google-gets-total-victory-over-authors-guild-book-scanning-is-fair-use.shtml.

"Commission Proposes Copyright Exception for Researchers." Research \& Innovation, European Commission, September I4, 20I6. http://ec.europa.eu/ research/index.cfm?pg=newsalert\&year=20I 6\&na=na-I409 I 6 .

“Copyright Act I9I I." The National Archives. http:/www.legislation.gov.uk/ ukpga/Geo5/I-2/46/enacted.

"The Copyright and Rights in Databases Regulations I997. Part III: Database Right.” National Archives, I997. http://www.legislation.gov.uk/ uksi/I997/3032/part/III/made.

“Copyright, Designs and Patents Act I988." The National Archives. http://www. legislation.gov.uk/ukpga/I988/48/contents.

Cordell, Ryan. “'Q i-Jtb the Raven’: Taking Dirty OCR Seriously.” 20I6. http:// ryancordell.org/research/qijtb-the-raven/.

Cox, Krista. "Text and Data Mining and Fair Use in the United States." Washington, DC: Association of Research Libraries, 20I 5. www.arl.org/storage/documents/TDM-5JUNE20I 5.pdf.

"Directive 20I2/28/EU of the European Parliament and of the Council on Certain Permitted Uses of Orphan Works." Strasbourg: Official Journal of the European Union, October 25, 20I 2. http://eur-lex.europa.eu/LexUriServ/LexUriServ.do?uri=OJ:L:20I 2:299:0005:00I 2:EN:PDF.

Easley, Alexis. "Chance Encounters, Rediscovery, and Loss: Researching Victorian Women Journalists in the Digital Age." Victorian Periodicals Review 49, no. 4 (2016): 694-7I7.

—. "The Nineteenth Century: Intellectual Property Rights and 'Literary Larceny." In The Cambridge Handbook of Literary Authorship, edited by Ingo Berensmeyer, Gert Buelens, and Marysa Demoor. Cambridge: Cambridge University Press, forthcoming.

Fagan, Benjamin. "Chronicling White America." American Periodicals: A Journal of History \& Criticism 26, no. I (2016): IO-I3.

Fyfe, Paul. "An Archaeology of Victorian Newspapers.” Victorian Periodicals Review 49, no. 4 (2016): 546-77. 
Gabriele, Sandra. "Transfiguring the Newspaper: From Paper to Microfilm to Database.” Amodern 2 (2OI4). http://amodern.net/article/transfiguring-thenewspaper/.

Gadd, Ian. "The Use and Misuse of Early English Books Online.” Literature Compass 6, no. 3 (2009): 680-92.

Geiger, Christopher, Giancarlo Frosio, and Oleksandr Bulayenko. "Opinion of the CEIPI on the European Commission's Proposal to Reform Copyright Limitations and Exceptions in the European Union.” Infojustice.org, October I 8, 20I7. http://infojustice.org/archives/38924.

Gibbs, Frederick W., and Daniel J. Cohen. "A Conversation with Data: Prospecting Victorian Words and Ideas.” Victorian Studies 54, no. I (Autumn 20I I): 69-77.

Hardy, Molly O’Hagan. "Bibliographic Enterprise and the Digital Age: Charles Evans and the Making of Early American Literature." American Literary History 29, no. 2 (20I7): 33 I-5I.

Hargreaves, Ian. "Digital Opportunity: Review of Intellectual Property and Growth,” 20I I. https://www.gov.uk/government/publications/digital-opportunity-review-of-intellectual-property-and-growth.

Hughes, Lorna M. "Live and Kicking: The Impact and Sustainability of Digital Collections in the Humanities." In Proceedings of the Digital Humanities Congress 2OI2. University of Sheffield: HRI Online Publications, 20I2. https:// www.hrionline.ac.uk/openbook/chapter/dhc-hughes.

. "The Public Has a Right to Memory." OurBeeb: The Future of the BBC (blog), June 23, 20I 5. https://www.opendemocracy.net/ourbeeb/lorna-hughes/ public-has-right-to-memory.

Humphreys, Alex. “On Beyond Keyword Search.” JSTOR Labs (blog), March 6, 20I7. http://labs.jstor.org/blog/\#!on_beyond_keyword_search-introducing_ text_analyzer.

Intellectual Property Office. "Consultation on Reducing the Duration of Copyright in Unpublished ("2039") Works in Accordance with Section I70(2) of the Copyright, Designs and Patents Act 1988.” Intellectual Property Office, 20I4. https://assets.publishing.service.gov.uk/government/uploads/system/ uploads/attachment_data/file/3688 I I/consultation-on-unpublished-works.pdf.

- "Exceptions to Copyright: Research." Intellectual Property Office, October 20I4. https://www.gov.uk/government/uploads/system/uploads/attachment_data/file/375954/Research.pdf.

Jockers, Matthew. Macroanalysis: Methods for Digital Literary History. Champaign: University of Illinois Press, 2013.

Jockers, Matthew L., Matthew Sag, and Jason Schultz. "Brief of Digital Humanities and Law Scholars as Amici Curiae in Authors Guild v. Google.” SSRN Scholarly Paper. Rochester: Social Science Research Network, August 3, 2012. http://papers.ssrn.com/abstract=2 102542 . 
"Brief of Digital Humanities and Law Scholars as Amici Curiae in Authors Guild v. Hathitrust.” SSRN Scholarly Paper. Rochester: Social Science Research Network, June 4, 20I3. http://papers.ssrn.com/abstract=2274832.

Kelly, John. "The Text and Data Mining Copyright Exception: Benefits and Implications for UK Higher Education.” JISC, February 9, 20I6. https://www.jisc. ac.uk/guides/text-and-data-mining-copyright-exception.

King, Ed. "British Library Digitisation: Access and Copyright.” Proceedings of the World Library and Information Congress. Quebec: International Federation of Library Associations, 2008.

Lansdall-Welfare, Thomas, Saatviga Sudhahar, James Thompson, Justin Lewis, FindMyPast Newspaper Team, and Nello Cristianini. "Content Analysis of I 50 Years of British Periodicals." Proceedings of the National Academy of Sciences, January 9, 20I7. http://www.pnas.org/content/I I 4/4/E457.

Leary, Patrick. "Googling the Victorians." Journal of Victorian Culture Io, no. I (2005): 72-86.

Liddle, Dallas. "Genre: 'Distant Reading' and the Goals of Periodicals Research." Victorian Periodicals Review 48, no. 3 (201 5): 383-402.

- "The News Machine: Textual Form and Information Function in the London Times, I785-I885.” Book History I9, no. I (2016): I32-68.

Mak, Bonnie. "Archaeology of a Digitization." Journal of the American Society for Information Science and Technology 65, no. 8 (August 20I4): I 5 I 5-26.

McDonald, Diane, and Ursula Kelly. "Value and Benefits of Text Mining." JISC, March I 4, 20I2. https://www.jisc.ac.uk/reports/value-and-benefits-of-textmining.

Michel, Jean-Baptiste, Yuan Kui Shen, Aviva Presser Aiden, Adrian Veres, Matthew K. Gray, The Google Books Team, Joseph P. Pickett, et al. "Quantitative Analysis of Culture Using Millions of Digitized Books." Science 33 I, no. 60I 4 (20II): I76-82.

Milligan, Ian. "Illusionary Order: Online Databases, Optical Character Recognition, and Canadian History, I997-2010." Canadian Historical Review 94, no. 4 (2013): 540-69.

Murray-Rust, Peter. "Content Mining Starts Today! And We Have the Technology.” Petermr's Blog (blog), June I, 20I4. https://blogs.ch.cam.ac.uk/ $\mathrm{pmr} / 20 \mathrm{I}$ 4/06/or/content-minings-starts-today-and-we-have-the-technology/.

Mussell, Jim. "The British Newspaper Archive (BNA).” Jimmussell.com (blog), January 9, 20I 2. http://jimmussell.com/20I 2/OI/o9/the-british-newspaperarchive-bna/.

Nicholson, Bob. "Counting Culture; or, How to Read Victorian Newspapers from a Distance." Journal of Victorian Culture I7, no. 2 (20I2): 238-46.

“Our Research Center." HathiTrust Digital Library, 201 5. https://www. hathitrust.org/htrc. 
Prescott, Andrew. "Dennis the Paywall Menace Stalks the Archives." Digital Riffs (blog), February 2, 20I4. http://digitalriffs.blogspot.com/20I4/O2/dennis-paywall-menace-stalks-archives.html.

Putnam, Lara. "The Transnational and the Text-Searchable: Digitized Sources and the Shadows They Cast." American Historical Review I2 I, no. 2 (April 2016): 377-402.

Rose, Mark. Authors and Owners: The Invention of Copyright. Cambridge: Harvard University Press, I993.

Sample, Mark. "The Poetics of Non-Consumptive Reading.” Sample Reality (blog), May 22, 20I3. http://www.samplereality.com/20I3/05/22/the-poeticsof-non-consumptive-reading/.

Scheid, Maria. "New DMCA Exemptions." Copyright Corner, Ohio State University Libraries (blog), December 30, 20I 5. https://library.osu.edu/blogs/copyright/20 I 5/I 2/30/new-dmca-exemptions/.

Shaw, Jane. "Io Billion Words: The British Library British Newspapers I 800I900 Project. Some Guidelines for Large-Scale Newspaper Digitisation.” In Libraries-A Voyage of Discovery. IFLA General Conference and Council, 2005. http://www.webarchive.org.uk/wayback/archive/20I406I 5090I 56/ http://www.jisc.ac.uk/uploaded_documents/IFLA_2005.pdf.

_. "British Newspapers I620-I900: Final Report." JISC and the British Library, August 2009. http://www.webarchive.org.uk/wayback/ archive/20I 406I 4080I 34/http://www.jisc.ac.uk/media/documents/programmes/digitisation/blfinal.pdf.

Sherratt, Tim. "4 Million Articles Later.” Discontents (blog), June 29, $20 \mathrm{I} 2$. http://discontents.com.au/4-million-articles-later/.

Slauter, Will. Who Owns the News?: A History of Copyright. Stanford: Stanford University Press, forthcoming.

Tudur, Dafydd. "Getting It Right.” Paper presented at Through the Copyright Jungle, Library and Archives, Bangor University, November I I, 20I 4. https:// www.bangor.ac.uk/library/copyright/copyright-jungle.php.en.

United States Copyright Office. "Section I08 of Title I7: A Discussion Document of the Register of Copyrights.” Washington, DC: United States Copyright Office, September 20I7. https://www.copyright.gov/policy/section Io8/discussion-document.pdf.

Werner, Sarah. "Researching While Unaffiliated.” Wynken de Worde (blog), September 30, 2016. http://sarahwerner.net/blog/2016/og/researching-whileunaffiliated/.

Wharton, Robin. "Digital Humanities, Copyright Law, and the Literary." Digital Humanities Quarterly 7, no. I (2013). http://www.digitalhumanities.org/dhq/ $\mathrm{vol} / 7 / \mathrm{I} / 000 \mathrm{I} 47 / 000 \mathrm{I} 47 \cdot \mathrm{html}$. 